Research Paper

\title{
Eifects of Diosgenin on Myometrial Matrix Metalloproteinase-2 and -9 Ac- tivity and Expression in Ovariectomized Rats
}

\author{
Chi-Chen Chang 1, , Tang-Ching Kuan 1, , Yao-Yuan Hsieh², Ying-Jui Ho ${ }^{3}$, Yu-Ling Sun ${ }^{4}$, Chih-Sheng Lin1, ${ }^{1, \bigotimes}$
}

1. Department of Biological Science and Technology, National Chiao Tung University, Hsinchu, Taiwan.

2. School of Chinese Medicine, College of Chinese Medicine, China Medical University, Taichung, Taiwan.

3. School of Psychology, Chung Shan Medical University, Taichung, Taiwan.

4. Division of Biotechnology, Animal Technology Institute Taiwan, Miaoli, Taiwan

${ }^{*}$ Equal contribution as the first author.

Corresponding author: Chih-Sheng Lin, Ph.D., Department of Biological Science and Technology, National Chiao Tung University, No.75 Po-Ai Street, Hsinchu 30068, Taiwan, R.O.C. Tel: 886-3-5131338; Fax: 886-3-5729288; E-mail: lincs@mail.nctu.edu.tw

() Ivyspring International Publisher. This is an open-access article distributed under the terms of the Creative Commons License (http://creativecommons.org/ licenses/by-nc-nd/3.0/). Reproduction is permitted for personal, noncommercial use, provided that the article is in whole, unmodified, and properly cited.

Received: 2011.02.24; Accepted: 2011.07.07; Published: 2011.07.13

\begin{abstract}
Diosgenin, a traditional Yam extraction, has been used in hormone replacement for menopausal women. We aimed to investigate the influences of diosgenin administration upon the MMP-2 and -9 activity and expression and reproductive hormones of ovariectomized (OVX) rats, a model of menopausal status. Seven-week old female Wistar rats with bilateral OVX or sham operation (controls) were divided and administered different dosages of diosgenin $(0,10,50$, or $100 \mathrm{mg} / \mathrm{kg} /$ day $)$ for 8 weeks. Serum was then sampled for progesterone (P4) and estradiol (E2) assay and uterine horns harvested. Myometrial MMP-2 and -9 activity and expression were surveyed and myometrial collagen expression was also assayed. The results show higher body weight in OVX rats across the 8 weeks post surgery and no significant differences were noted among OVX or Sham rats with diosgenin supplements. There were lower P4 and E2 concentrations in OVX rats compared to Sham rats, and higher P4 concentration of Sham rats post diosgenin supplement. MMP-2 and -9 mRNA expression and activity was lower in OVX rats, although higher MMP-2 and lower MMP-9 activity/mRNA expression was observed in OVX rats post diosgenin supplementation. Collagen mRNA expression was higher in OVX rats compared to Sham controls, and diosgenin administration decreased collagen mRNA expression in OVX rats. In conclusion, diosgenin is associated with gelatinase expression and collagen metabolism in OVX rats. Diosgenin administration can partially reverse the effects of OVX upon MMP functions and hormone status. Adequate diosgenin supplement might modulate myometrial gelatinase expression and collagen metabolism in menopausal subjects.
\end{abstract}

Key words: diosgenin, gelatinase, matrix metalloproteinase, myometrium, ovariectomization

\section{Introduction}

Hormone replacement therapy (HRT) is one of the most commonly prescribed medicines for menopausal women. Estrogen replacement therapy can decrease the risk of developing numerous disorders, including osteoporosis [1], Alzheimer's disease [2], vasomotor symptoms [3], cardiovascular diseases [4], etc. Synthetic estrogen, the current most effective agent for HRT, is widely used in menopausal women. However, several studies suggest that traditional HRT is not effective in reducing the risk of some meno- 
pause-related disorders [5, 6]. Therefore, many patients seek alternative modalities for symptomatic relief. The requests for complementary or alternative therapies for hormone replacement have increased substantially. One of the current popular treatments is wild yam. Wild yam or diosgenin (extracted from the root of wild yam) has been widely used for alternative HRT $[7,8]$.

Many menopausal women use traditional herb medicines, such as wild yam extract or diosgenin, to restore gonadal hormones and therefore minimize post-menopausal symptoms. Yam is composed of some steroidal saponins, which may influence endogenous steroidogenesis [9]. Administration of yam was reported to increase the status of sexual hormones, lipids, and antioxidants in postmenopausal women [10]. Diosgenin, one type of steroidal saponin, is extracted from the root of wild yam and has been used in numerous medical applications. It was reported that short-term treatment with diosgenin-enriched yam extract in women suffering from menopausal symptoms is free of side-effects, but appears to have little effect on menopausal symptoms [9]. However, the results from animal models show that diosgenin supplementation could affect the kidney and adrenal gland functions, and improve the epidermal thickness in ovariectomized (OVX) rats [8, $11,12]$. As a result, it was proposed that diosgenin supplementation would stimulate the production of ovarian hormones in OVX rats. Endometrial function is known to be influenced by the ovarian hormones, estradiol and progesterone. Ovarian hormones and function are closely associated with endometrial and uterus statuses. However, the mechanisms by which the lack of ovarian hormone influences the molecular biology of uterus are poorly understood. Moreover, the effects of wild yam or diosgenin upon menopausal individuals remain obscure. Information about the efficacy and pharmacodynamics for these natural medicines upon menopausal individuals are lacking.

Matrix metalloproteinases (MMPs), a family of zinc-dependent proteinases, are essential for some physiological and pathological processes, such as wound repair [13], cardiovascular diseases [14], rheumatoid arthritis [15], cancer invasion and metastasis [16]. MMPs are required for the extracellular matrix remodeling [17] and the activities of MMPs depend on the balance of their activators and inhibitors, and balanced gelatinase activity can mediate endometrial remodeling $[18,19]$. MMPs and collagen might influence the development of adenomyosis [20] and leiomyoma [21]. Estrogen might stimulate the collagen biosynthesis and modulates MMPs activity in uterine leiomyoma, which further contributes to the development of leiomyoma [21]. Activity of MMPs was significantly higher in leiomyomas than that in myometrium, which suggests its roles upon uterine neoplasm [22]. Compromised MMPs and collagen synthesis are associated with leiomyoma cell growths in-vitro [23].

Understanding the balance between MMPs activity and collagen metabolism in post-menopausal women might open new strategies for therapeutic interventions for uterine modeling and neoplasm. To the best of our knowledge, no investigators have demonstrated the effects of diosgenin administration upon the uterine MMP and collagen expressions in menopausal individuals. Only few investigators demonstrated the effects of diosgenin treatment upon MMP or collagen expression in tumor cells [24] and leukemia disorders [25]. The aim of this study was to describe the effects of diosgenin supplementation upon the mRNA expression and activity of MMP-2 and -9 , and collagen in the myometrial tissue of rats after OVX.

\section{Materials and Methods}

\section{Experimental animals and treatments}

Seven-week old female Wistar rats $(245 \pm 2 \mathrm{~g}$; $\mathrm{n}=$ 48; BioLASCO Taiwan Co., Ltd., Taiwan) were housed in groups of three in acrylic cages $(35 \times 56 \times 19 \mathrm{~cm})$ in an animal room with a $12 \mathrm{~h}$ light/dark cycle (lights on at 7:00 am) with food and water provided ad libitum. All experimental procedures were performed according to the NIH Guide for the Care and Use of Laboratory Animals. All survey procedures were approved by the Animal Care Committee of Chung Shan Medical University (IACUC approval No. 273).

The procedure used for OVX was performed as previously described [26]. Briefly, the rats were anesthetized by means of the intraperitoneal injection of 2 $\mathrm{mg} / \mathrm{kg}$ of Zoletil 50 (Virbac, France) and the ovaries were retracted and removed. Immediately following surgery, each rat was injected with Penicillin-G procaine (20,000 IU, i.m.). The sham-operated group underwent the same surgical procedure except for the removal of the ovaries. After surgery, the rats were kept individually in acrylic cages for recovery for 7 days, and then regrouped in their home cages.

\section{Diosgenin administration}

Diosgenin purchased from Sigma (St. Louis, MO, USA) was wrapped in a ball of bread (about $1 \mathrm{~g}$ ) and fed daily to each rat. Four weeks after OVX, the rats were given diosgenin $(0,10,50$, or $100 \mathrm{mg} / \mathrm{kg} /$ day $)$ orally for 8 weeks. On the $56^{\text {th }}$ day after diosgenin administration, the serum of animals was sampled for 
the measurements of progesterone (P4) and estradiol (E2) concentration. The rats were then sacrificed using $\mathrm{CO}_{2}$ and their uteruses (myometrium) were removed and frozen immediately (within $10 \mathrm{~min}$ ) in liquid nitrogen and stored at $-80^{\circ} \mathrm{C}$ until use for RNA or protein extraction.

\section{Measurements of estradiol and progesterone}

Concentrations of serum E2 and P4 were quantified by a radioimmunoassay method [27] using a Delfia assay kit (PerkinElmer Life and Analytical Sciences, Wallac Oy, Turku, Finland) according to the supplier's recommendations. All samples were tested as duplicates within a single assay and the concentrations of E2 and P4 were calculated according to the standard curves.

\section{Protein extraction and electrophoresis}

Protein extraction, electrophoresis, and Western blot were performed as previously described [28]. The myometrial tissue $(200 \mathrm{mg}$ ) was homogenized in $1 \mathrm{ml}$ of ice-cold lysis buffer containing $20 \mathrm{mM}$ Tris- $\mathrm{HCl}, \mathrm{pH}$ 7.6, $1 \mathrm{mM}$ dithiothreitol, $200 \mathrm{mM}$ sucrose, $1 \mathrm{mM}$ EDTA, $0.1 \mathrm{mM}$ sodium orthovanadate, $10 \mathrm{mM}$ sodium fluoride, $0.5 \mathrm{mM}$ phenylmethylsulfonyl fluoride and $1 \%(\mathrm{v} / \mathrm{v})$ Triton $\mathrm{X}-100$. The homogenates were then centrifuged at $12,000 \times g$ for $15 \mathrm{~min}$ at $4^{\circ} \mathrm{C}$. Supernatants were collected, and the protein concentration was determined by Bio-Rad protein assay kit (Bio-Rad Laboratories, Hercules, CA, USA) with bovine serum albumin as a standard.

\section{Gelatin zymography}

The MMP-2 and -9 activities in the myometrial homogenate were surveyed by a gelatinase zymography assay. Zymography was performed by using gelatin-containing gels as described by Chen $e t$ al. [29]. Briefly, $30 \mu \mathrm{g}$ of uterus homogenate was mixed with $2 \times$ zymography sample buffer $(0.125 \mathrm{M}$ Tris- $\mathrm{HCl}, \mathrm{pH}=6.8,20 \%$ [v/v] glycerol, $4 \%$ [w/v] SDS, $0.005 \%$ bromophenol blue) incubated for $10 \mathrm{~min}$ at room temperature, and then loaded into each lane of an $10 \%$ sodium dodecyl sulfate polyacrylamide gel (SDS-PAGE) containing $0.1 \mathrm{mg} / \mathrm{ml}$ gelatin (Sigma). Following electrophoresis, the gel was washed twice for $30 \mathrm{~min}$ in zymogram renaturing buffer $(2.5 \%$ Triton X-100) with gentle agitation at room temperature to remove SDS, then incubated overnight at $37^{\circ} \mathrm{C}$ in reaction buffer $(50 \mathrm{mM}$ Tris- $\mathrm{HCl}, \mathrm{pH} 7.4,200 \mathrm{mM}$ $\mathrm{NaCl}$, and $5 \mathrm{mM} \mathrm{CaCl}$ ). After Coomassie brilliant blue staining, gelatinase activities were identified as clear zones against a blue background. Gelatinase activities in the gel slabs were quantified using Scion Image software (NIH, Bethesda, MD, USA), which quantifies the extent of lysis in bands containing gelatinase. A MMP-2 or -9 positive controls (Chemicon, Temecula, CA, USA) was loaded in each gel as a standard to normalize density values, and band intensities are expressed in arbitrary units.

\section{Western blotting}

An amount of $20 \mu \mathrm{g}$ of protein extract of each sample separated by SDS-PAGE was electrophoretically transferred to polyvinylidene fluoride (PVDF) membranes (Immobilon-PTM; Millipore, Bedford, MA, USA). After blocking, primary antibodies against collagen type I (anti-collagen type I, \#ab6308; Abcam, Cambridge, MA, USA) or glyceraldehyde-3-phophate-dehydrogenase (anti-GAPDH, \#sc20357; Santa Cruz Biotechnology, Santa Cruz, CA, USA) were used at a dilution of 1:1,000, and the HRP-labeled secondary antibody against goat IgG (\#sc2020; Santa Cruz Biotechnology) or rabbit IgG (\#sc2004; Santa Cruz Biotechnology) was applied using a dilution of 1:2,000. Substrates were visualized using ECL western blotting detection reagents according to the manufacturer's instructions (Western Lightning ${ }^{\mathrm{TM}}$ Chemiluminescence Reagent Plus; PerkinElmer, Boston, MA, USA) and subsequent exposure of the membranes to X-ray film (Super $\mathrm{Rx}$ Medical X-Ray Film; Fujifilm, Kanagawa, Japan). Band intensity was quantified using densitometric analysis by imaging software (Image ${ }^{\mathrm{TM}}$; National Institute of Mental Health, Bethesda, MD, USA). The amounts of collagen type I were expressed relative to the amount of GAPDH in respective samples.

\section{RNA extraction}

Total cellular RNA extraction from the myometrial tissues and RNA quantification were performed according to our previous report [28]. In brief, $200 \mathrm{mg}$ of uterus tissue was homogenized on ice by a rotor-stator-type tissue homogenizer in $1 \mathrm{ml}$ TRIzol reagent (GIBCO BRL, Gaithersburg, MD, USA). Cellular debris was removed by centrifugation for $10 \mathrm{~min}$ at $12,000 \times g$ at $4^{\circ} \mathrm{C}$. RNA was precipitated by adding equal volumes of isopropanol and then washing with $75 \%$ ethanol. The resultant RNA was further purified with the RNeasy Midi kit (Qiagen, Valencia, CA, USA) according to the manufacturer's instructions. The amount of total RNA was determined spectrophotometrically at $260 \mathrm{~nm}$, and the integrity was confirmed by analysis on a denaturing agarose gel.

\section{Semi-quantitative reverse transcrip- tion-polymerase chain reaction (RT-PCR)}

The mRNA expressions of MMP-2 and -9 in the myometrium were surveyed by RT-PCR according to 
the procedure reported by Lin et al. [30]. For cDNA synthesis, five $\mu \mathrm{g}$ RNA was reverse-transcribed in a total reaction volume of $20 \mu \mathrm{l}$ with $1 \times$ reverse transcription buffer, $0.5 \mathrm{mM}$ dNTPs, $2.5 \mu \mathrm{M}$ oligo-dT (TOYOBO, Osaka, Japan), $1 \mathrm{U} / \mu \mathrm{l}$ RNase inhibitor (TOYOBO), and $5 \mathrm{U} / \mu \mathrm{l}$ ReverTra Ace $^{\mathrm{TM}}$ reverse transcriptase (TOYOBO). After reaction for $60 \mathrm{~min}$ at $42^{\circ} \mathrm{C}$, the mixture was incubated for $5 \mathrm{~min}$ at $95^{\circ} \mathrm{C}$ to denature the cDNA products. RT-PCR primers and conditions are shown in Table 1 . The PCR reactions contained $2 \mu \mathrm{l}$ cDNA, $3 \mu \mathrm{l}$ each primer $(10 \mu \mathrm{M}), 5 \mu \mathrm{l}$ of 10× PCR buffer, $2 \mu \mathrm{l}$ of $10 \mathrm{mM}$ dNTPs, $1 \mu \mathrm{l}$ of $5 \mathrm{U} / \mu \mathrm{l}$ Taq polymerase (Promega, Madison, WI, USA), and $35 \mu \mathrm{l}$ distilled water in a total volume of $50 \mu \mathrm{l}$. Thermal cycler (MiniCycler ${ }^{\text {TM }}$; MJ Research, Waltham, MA, USA) condition for each gene amplification is shown in Table 1. For the semi-quantitative RT-PCR, the number of cycles for each gene was optimized to ensure that the reaction was within the linear amplification range (data not shown). The resulting RT-PCR products were visualized on $1.5 \%$ agarose gels stained with SYBR Safe DNA gel stain (Invitrogen, Eugene, OR, USA). The stained image was recorded by an image analyzer (Kodak DC290 Digital camera System $^{\text {TM}}$; Eastman Kodak, Rochester, NY, USA). Band intensity of PCR DNA was quantified using densitometric analysis by Scion image ${ }^{\mathrm{TM}}$. The relative mRNA expression of MMP-2 and -9 were normalized to GAPDH expression.

\section{Statistical analysis}

To analyse the effects of surgery and diosgenin treatment, two-way analysis of variance (ANOVA) was carried out. When interactions existed, the independent $t$-test was used to analyze the effects of OVX procedures. To evaluate the effects of diosgenin treatment, one-way ANOVA was performed, followed by the least significant difference (LSD) post hoc test. All results are expressed as the mean \pm SEM. The level of significance was defined as $p$-value $<0.05$.

\section{Results}

\section{Effects of OVX and diosgenin on BW}

During the experimental period of 8 weeks, a trend of higher BW in OVX animals compared to Sham-operated animals was observed (Table 2). In OVX rats, 4-weeks diosgenin supplements (10, 50, and $100 \mathrm{mg} / \mathrm{kg} /$ day) significantly increased BW compared to Sham rats with similar-dosage diosgenin supplementation $(p<0.05)$. We also observed the non-significantly difference of BW between the different dosage of diosgenin supplementation in both groups. There were no obvious side effects in the animals after diosgenin administration during our experiment.

\section{Effects of OVX and diosgenin on reproductive hormones}

Lower serum P4 and E2 concentrations were observed in OVX rats compared to Sham rats $(p<$ $0.05)$. In the groups without diosgenin supplementation, serum P4 and E2 concentrations in OVX rats were $43 \%(p<0.01)$ and $78 \%(p<0.05)$ lower than those determined in Sham rats, respectively (Figure 1A and 1B). In Sham rats, diosgenin supplementation increased serum P4 but not E2 concentrations. The P4 concentration in Sham rats supplied with high dosage diosgenin $(100 \mathrm{mg} / \mathrm{kg} /$ day) was significantly increased by $56 \%(p<0.05)$ compared to Sham rats without diosgenin supplementation. However, the effect of diosgenin supplementation on increasing serum P4 in OVX rats was not observed (Figure 1A). There was no effect of diosgenin on serum E2 observed in OVX groups (Figure 1B).

Table 1. The PCR primer sequences, protocols, and product sizes for MMP-2, MMP-9, and GAPDH used to assay gene expression by RT-PCR.

\begin{tabular}{|c|c|c|c|c|}
\hline Gene & Accession no. & Forward/Reverse primers sequence $\left(5^{\prime} \rightarrow 3^{\prime}\right)$ & PCR amplification protocol (cycle no.) & $\begin{array}{l}\text { PCR product } \\
\text { size }(\mathrm{bp})\end{array}$ \\
\hline MMP-2 & NM_031054 & $\begin{array}{l}\text { F-GTCCTGACCAAGGATATAGCC } \\
\text { R-AGACCCAGTACTCATTCCCTG }\end{array}$ & $\begin{array}{l}94^{\circ} \mathrm{C}, 5 \mathrm{~min} \rightarrow\left[94^{\circ} \mathrm{C}, 30 \mathrm{sec} \rightarrow 55^{\circ} \mathrm{C}, 30 \mathrm{sec}\right. \\
\left.\rightarrow 72^{\circ} \mathrm{C}, 45 \mathrm{sec}\right](30) \rightarrow 72^{\circ} \mathrm{C}, 3 \mathrm{~min}\end{array}$ & 465 \\
\hline MMP-9 & U24441 & $\begin{array}{l}\text { F-GCTGCACCACCTTACCGGCCCTTTTATTTA } \\
\text { R-TGGTTATCCTTCCACTGAGGGATCATCTCG }\end{array}$ & $\begin{array}{l}94^{\circ} \mathrm{C}, 5 \mathrm{~min} \rightarrow\left[94^{\circ} \mathrm{C}, 30 \mathrm{sec} \rightarrow 61^{\circ} \mathrm{C}, 30 \mathrm{sec}\right. \\
\left.\rightarrow 72^{\circ} \mathrm{C}, 45 \mathrm{sec}\right](40) \rightarrow 72^{\circ} \mathrm{C}, 3 \mathrm{~min}\end{array}$ & 458 \\
\hline GAPDH & AF_261085 & $\begin{array}{l}\text { F-TGGCGCTGAGTACGTCGTG } \\
\text { R-TTCAGCTCAGGGATGACCTT }\end{array}$ & $\begin{array}{l}94^{\circ} \mathrm{C}, 5 \mathrm{~min} \rightarrow\left[94^{\circ} \mathrm{C}, 30 \mathrm{sec} \rightarrow 56^{\circ} \mathrm{C}, 30 \mathrm{sec}\right. \\
\left.\rightarrow 72^{\circ} \mathrm{C}, 45 \mathrm{sec}\right](20) \rightarrow 72^{\circ} \mathrm{C}, 3 \mathrm{~min}\end{array}$ & 413 \\
\hline
\end{tabular}

MMP-2: matrix metalloproteinase-2; MMP-9: matrix metalloproteinase-9; GAPDH: glyceraldehyde-3-phophate dehydrogenase

For the accuracy quantitative RT-PCR, the number of cycles for each gene has been optimized to ensure that the reaction is within the linear amplification range (data not shown). 
Table 2. Comparisons of body weight between Sham controls and ovariectomized (OVX) rats during 8-week diosgenin administration $(0,10,50$, or $100 \mathrm{mg} / \mathrm{kg} /$ day $)$.

\begin{tabular}{|c|c|c|c|c|c|c|c|c|}
\hline Body weight (g) & 1 week & 2 week & 3 week & 4 week & 5 week & 6 week & 7 week & 8 week \\
\hline \multicolumn{9}{|l|}{ Sham rats $(n=24)$} \\
\hline $0 \mathrm{mg} / \mathrm{kg} /$ day & $253 \pm 14$ & $263 \pm 12$ & $273 \pm 15$ & $289 \pm 6$ & $289 \pm 21$ & $293 \pm 11$ & $294 \pm 13$ & $299 \pm 33$ \\
\hline $10 \mathrm{mg} / \mathrm{kg} /$ day & $252 \pm 12$ & $257 \pm 17$ & $275 \pm 13$ & $278 \pm 5$ & $282 \pm 22$ & $285 \pm 25$ & $278 \pm 23$ & $292 \pm 30$ \\
\hline $50 \mathrm{mg} / \mathrm{kg} /$ day & $238 \pm 12$ & $251 \pm 21$ & $260 \pm 15$ & $270 \pm 5$ & $272 \pm 30$ & $278 \pm 26$ & $281 \pm 20$ & $288 \pm 26$ \\
\hline $100 \mathrm{mg} / \mathrm{kg} /$ day & $253 \pm 8$ & $267 \pm 18$ & $277 \pm 17$ & $283 \pm 12$ & $283 \pm 27$ & $291 \pm 28$ & $290 \pm 23$ & $297 \pm 24$ \\
\hline \multicolumn{9}{|l|}{ OVX rats $(n=24)$} \\
\hline $0 \mathrm{mg} / \mathrm{kg} /$ day & $253 \pm 8$ & $271 \pm 15$ & $296 \pm 11$ & $307 \pm 12$ & $308 \pm 28$ & $319 \pm 26$ & $319 \pm 23$ & $327 \pm 22$ \\
\hline $10 \mathrm{mg} / \mathrm{kg} /$ day & $251 \pm 11$ & $269 \pm 18$ & $305 \pm 15$ & $317 \pm 11^{*}$ & $322 \pm 32^{* *}$ & $328 \pm 27^{* *}$ & $338 \pm 26^{* *}$ & $343 \pm 24^{* *}$ \\
\hline 50 mg/kg/day & $256 \pm 13$ & $280 \pm 29^{*}$ & $308 \pm 14^{* *}$ & $313 \pm 13^{* *}$ & $315 \pm 36^{* *}$ & $323 \pm 29 * *$ & $323 \pm 38^{*}$ & $331 \pm 27^{* *}$ \\
\hline $100 \mathrm{mg} / \mathrm{kg} /$ day & $246 \pm 9$ & $268 \pm 15$ & $293 \pm 12$ & $308 \pm 8^{*}$ & $313 \pm 36^{*}$ & $322 \pm 26^{*}$ & $323 \pm 27^{*}$ & $330 \pm 25^{*}$ \\
\hline
\end{tabular}

${ }^{*} p<0.05$ and ${ }^{* *} p<0.01$ compared to the parallel Sham rats

\section{A. Progesterone}

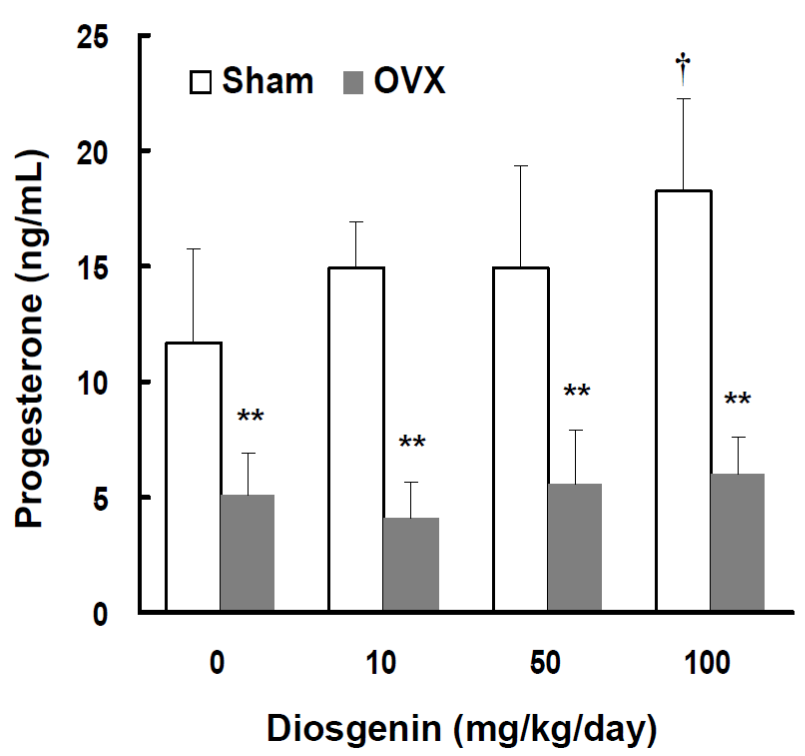

B. Estradiol

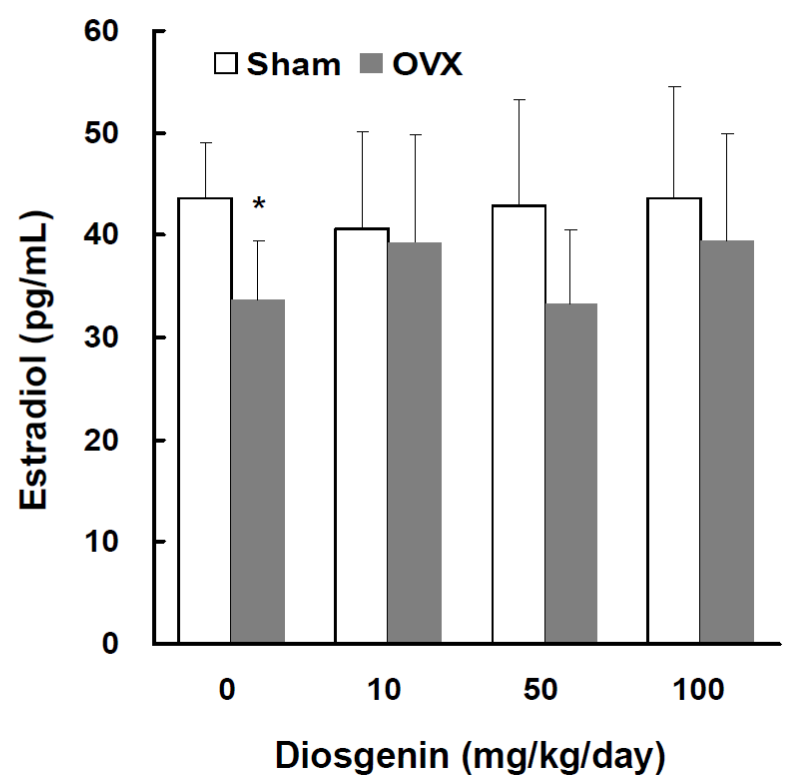

Figure 1. Comparisons of progesterone and estradiol concentrations between controls (Sham) and ovariectomized (OVX) rats after diosgenin supplementation $(0,10,50$, and $100 \mathrm{mg} / \mathrm{kg} /$ day). The serum estradiol (E2) and progesterone (P4) concentrations were measured in duplicate aliquots of each sample. Bar graphs of all values were expressed as the mean \pm SEM from six subjects. ${ }^{*} p<0.05$ and ${ }^{* *} p<0.01$ vs. the Sham groups; $\uparrow p<0.05$ vs. Diosgenin- 0 in the same group.

\section{Effects of OVX and diosgenin on serum calcium, phosphorous and glucose level}

The blood glucose level in OVX group was significantly higher than that in Sham group $(153 \pm 18$ vs. $128 \pm 20 \mathrm{mg} / \mathrm{dl} ; p<0.05)$. The serum calcium and phosphorous levels were $10.5 \pm 0.5$ and $7.3 \pm 0.6$ $\mathrm{mg} / \mathrm{dl}$ in sham-operated rats, and $10.4 \pm 0.6$ and $7.5 \pm$ 0.7 in OVX rats, respectively. The findings indicated that OVX surgery could not induce a significant change on serum calcium and phosphorous levels of OVX rats. Diosgenin supplementation also had no effect on serum calcium and phosphorous levels $(p>$ 0.05).The blood glucose levels were ranging from 115 to $140 \mathrm{mg} / \mathrm{dl}$ in Sham groups and from 120 to 148 $\mathrm{mg} / \mathrm{dl}$ in OVX groups supplied with 10, 50 and 100 $\mathrm{mg} / \mathrm{kg} /$ day diosgenin with no significant differences observed in both OVX rats and Sham rats $(p>0.05)$. 


\section{Effects of OVX and diosgenin on MMP-2 activity and expression}

In order to understand the effects of OVX and diosgenin supplement upon the expression and activity of gelatinases in myometrial tissues, we estimated the myometrial MMP-2 activity by gelatin zymography (Figure 2A) and gene expression by semi-quantitative RT-PCR (Figure 3A). The results illustrate significantly lower MMP-2 activity (Figure 2B) and also gene expression (Figure 3B) in OVX rats compared in Sham rats.
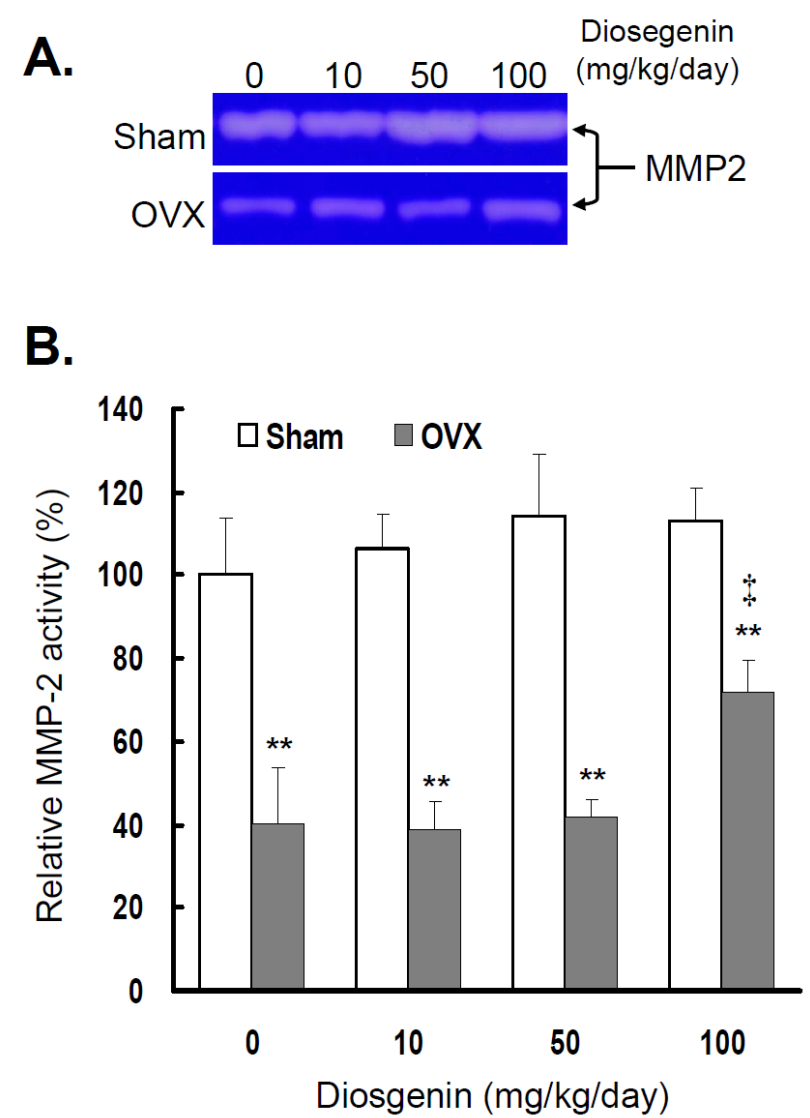

Figure 2. Comparisons of MMP-2 activity between controls (Sham) and ovariectomized (OVX) rats after diosgenin supplementation $(0,10,50$, or $100 \mathrm{mg} / \mathrm{kg} /$ day $)$. (A), MMP-2 activity was determined by gelatin zymography assay. The molecular weight of MMP-2 detected is approximately $72 \mathrm{kDa}$ shown on the gel. The bands of enzymatic activity shown are representatives of six identical determinations. (B), the relative MMP-2 activity affected by ovariectomization and diosgenin treatment was assayed. Bar graphs of all values were expressed as the mean \pm SEM from six subjects. ${ }^{* *} p<$ 0.01 vs. the Sham group; $\ddagger p<0.01$ vs. Diosgenin- 0 in the same group.

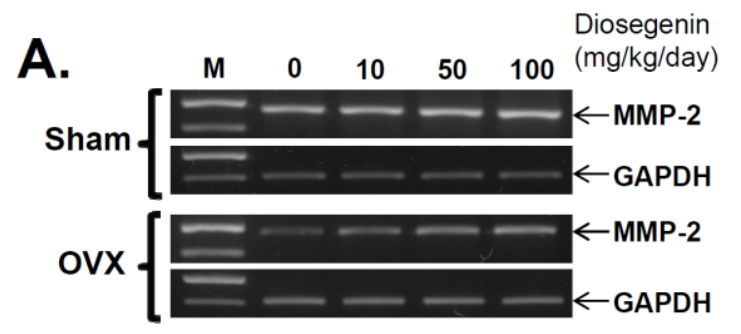

B.

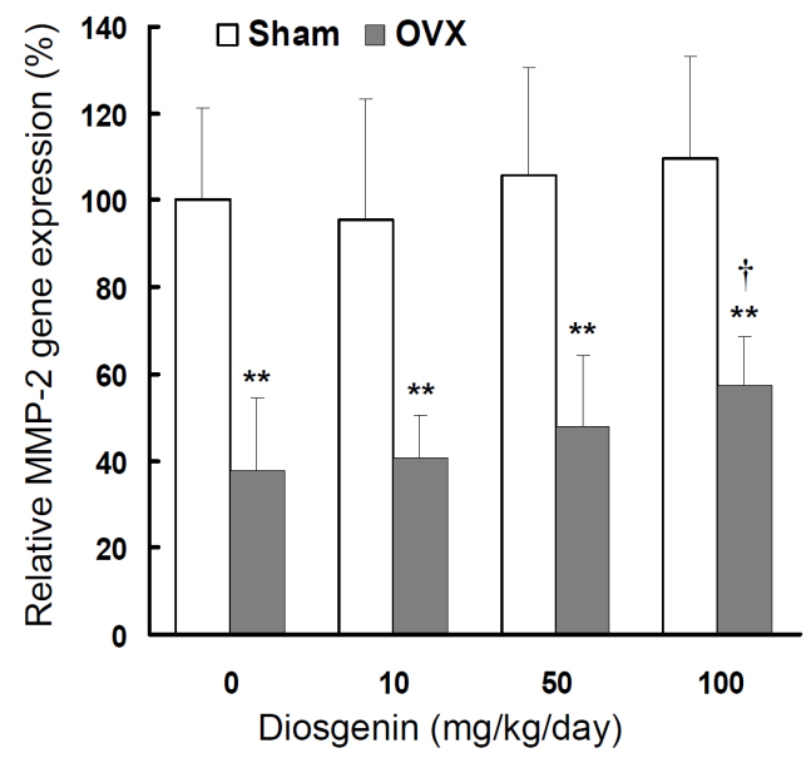

Figure 3. Comparisons of MMP-2 gene expression between controls (Sham) and ovariectomized (OVX) rats after diosgenin supplementation $(0,10,50$, or 100 $\mathrm{mg} / \mathrm{kg} /$ day). (A), MMP-2 gene expression was determined by semi-quantitative RT-PCR. The length of the PCR products for MMP-2 and GAPDH were $456 \mathrm{bp}$ and 413 bp, respectively. Amplification of GAPDH was determined as an internal control. The bands of PCR DNA shown are representatives of six identical determinations. (B), the relative MMP-2 gene expression affected by ovariectomization and diosgenin treatment was assayed. Bar graphs of all values were expressed as the mean \pm SEM from six subjects. ${ }^{* *} p<0.01 \mathrm{vs}$. Sham group; $\dagger p<0.05$ vs. Diosgenin-0 in the same group.

In the groups without diosgenin supplement, the relative MMP-2 activity and gene expression in OVX group was significantly reduced to $40 \%(p<0.01)$ and $38 \%(p<0.01)$ of those detected in Sham groups. In OVX rats, regardless of diosgenin dosage, MMP-2 activity and expression were still significantly lower than those of Sham groups $(p<0.05)$. Among OVX rats, administration of high-dosages (100 $\mathrm{mg} / \mathrm{kg} /$ day) of diosgenin supplementation increased both MMP-2 activity (Figure 2B) and gene expression (Figure 3B) compared to OVX rats without diosgenin 
supplementation $(p>0.05)$. In contrast, diosgenin supplementation did not significantly influence myometrial MMP-2 activity (Figure 2B) or gene expression (Figure 3B) in Sham rats $(p>0.05)$.

\section{Effects of OVX and diosgenin on MMP-9 activity and expression}

The effects of OVX and diosgenin on myometrial MMP-9 activity and expression were also determined by gelatin zymography (Figure $4 \mathbf{A}$ ) and semi-quantitative RT-PCR (Figure 5A), respectively.
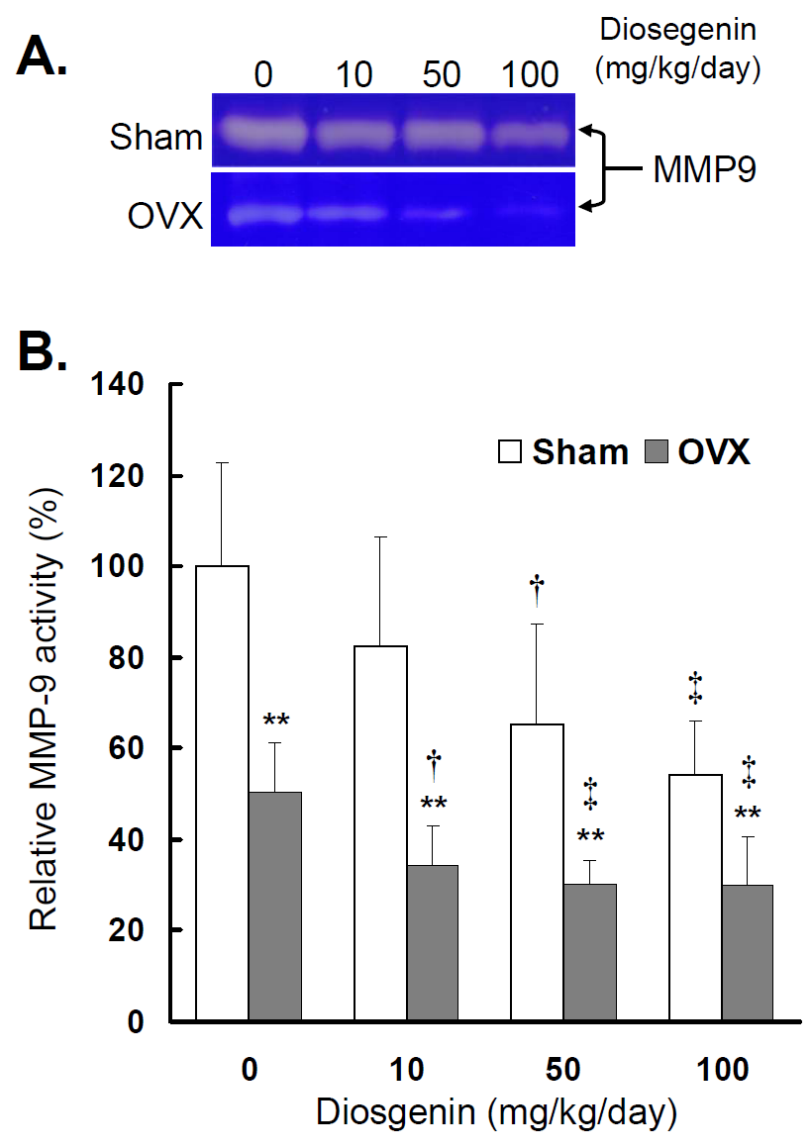

Figure 4. Comparisons of MMP-9 activity between controls (Sham) and ovariectomized (OVX) rats after diosgenin supplementation $(0,10,50$, or $100 \mathrm{mg} / \mathrm{kg} /$ day). (A), MMP-9 activity was determined by gelatin zymography assay. The molecular weight of MMP-9 detected is approximately $95 \mathrm{kDa}$ shown on the gel. The bands of enzymatic activity shown are representatives of six identical determinations. (B), the relative MMP-9 activity affected by ovariectomization and diosgenin treatment was assayed. Bar graphs of all values were expressed as the mean \pm SEM from six subjects. ${ }^{* *} p<$ 0.01 vs. Sham group ; †p<0.05 and $\ddagger p<0.01$ vs. Diosgenin- 0 in the same group.

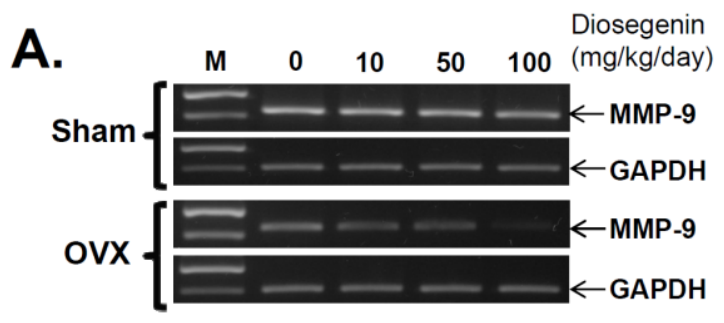

B.

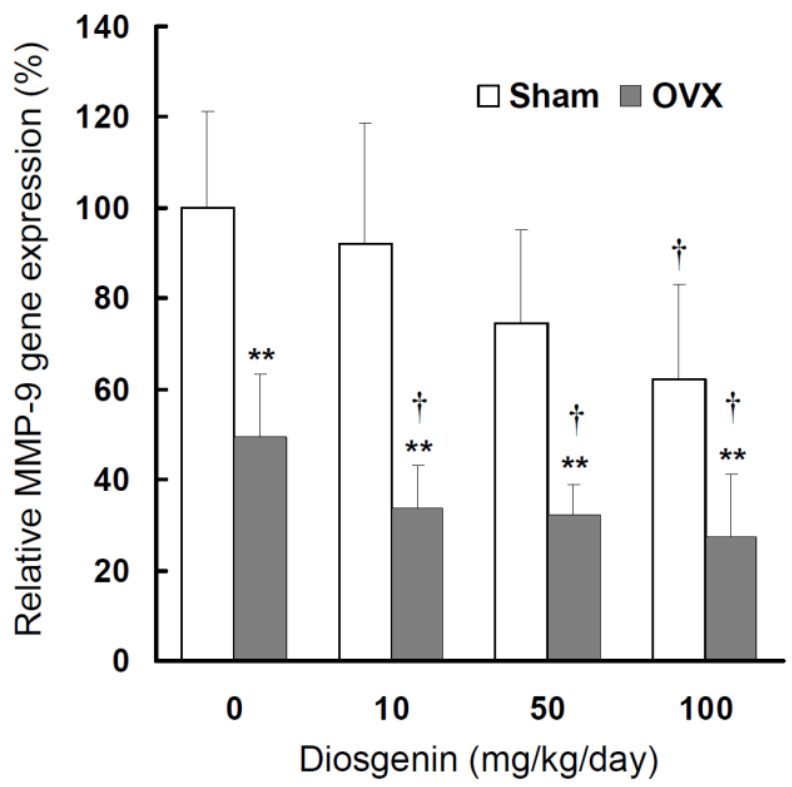

Figure 5. Comparisons of MMP-9 gene expression between controls (Sham) and ovariectomized (OVX) rats after diosgenin supplementation $(0,10,50$, or 100 $\mathrm{mg} / \mathrm{kg} /$ day). (A), MMP-9 gene expression was determined by semi-quantitative RT-PCR. The length of the PCR products for MMP-9 and GAPDH were 458 bp and 413 bp, respectively. Amplification of GAPDH was determined as an internal control. The bands of PCR DNA shown are representatives of six identical determinations. (B), the relative MMP-9 gene expression affected by ovariectomization and diosgenin treatment was assayed. Bar graphs of all values were expressed as the mean \pm SEM from six subjects. ${ }^{* *} p<0.01$ vs. Sham groups; $† p<0.05$ vs. Diosgenin- 0 in the same group.

Similar to myometrial MMP-2, significantly lower MMP-9 activity (Figure 4B) and gene expression (Figure 5B) were observed in OVX rats compared to Sham rats $(p<0.05)$. In the groups without diosgenin supplement, the relative MMP-9 activity and gene expression in OVX group were significantly reduced to $50 \%(p<0.01)$ and $49 \%(p<0.01)$ of those in Sham group. In OVX rats, diosgenin supplementation $(10,50$, and $100 \mathrm{mg} / \mathrm{kg} /$ day $)$ significantly decreased MMP-9 activity (Figure 4B) and gene expression 
(Figure 5B) compared to OVX rats without diosgenin supplementation. In Sham rats, higher dosages (50 and $100 \mathrm{mg} / \mathrm{kg} /$ day) of diosgenin supplementation also significantly decreased the MMP-9 activity and gene expression compared to those detected in Sham rats without diosgenin supplementation $(p<0.05$; Figure 4B and 5B).

\section{Effects of OVX and diosgenin on collagen ex- pression}

Western blots were used to determine type I collagen expression in myometrial tissues affected by OVX and diosgenin treatments, (Figure 6A).
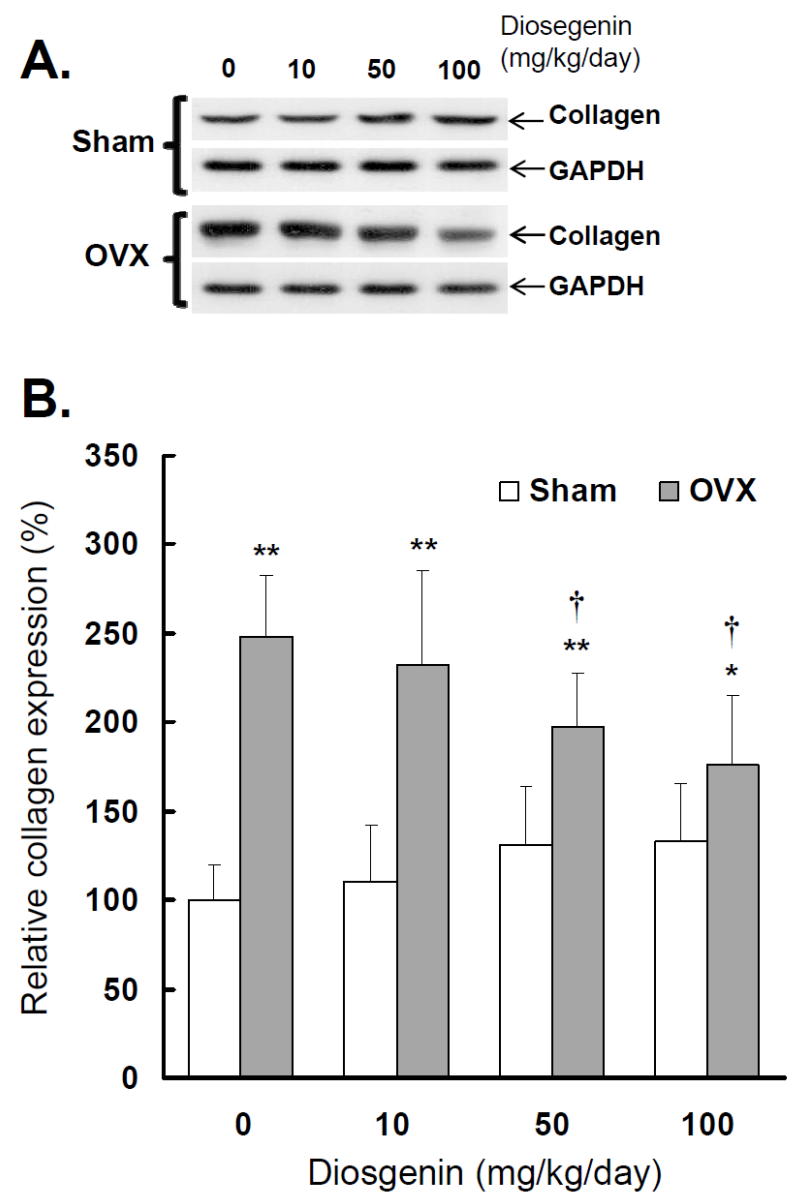

Figure 6. Comparisons of type I collagen expression between controls (Sham) and ovariectomized (OVX) rats after diosgenin treatment $(0,10,50$, or $100 \mathrm{mg} / \mathrm{kg} / \mathrm{day})$. (A), collagen expression was determined by Western blotting assay. The molecular weight of collagen detected is approximately $72 \mathrm{kDa}$. The Western blots shown are representatives of six identical determinations. (B), the relative collagen expression affected by ovariectomization and diosgenin treatment was assayed. Bar graphs of all values were expressed as the mean \pm SEM from six subjects. ${ }^{*} p<0.05$ and ${ }^{* *} p<0.01$ vs. Sham groups; $\dagger p<0.05$ vs. Diosgenin- 0 in the same group.
The results show a higher collagen expression in OVX rats compared to Sham rats $(p<0.05$; Figure 6B). Relative collagen expression in OVX rats was increased approximately $248 \%(p<0.01)$ compared to sham-operated controls. Collagen expression in OVX rats supplied with 10, 50 and $100 \mathrm{mg} / \mathrm{kg} /$ day diosgenin was reduced to be $93 \%, 73 \%(p<0.05)$ and $65 \%$ $(p<0.05)$ of that determined in OVX rats without diosgenin supplementation, respectively. In contrast, diosgenin administrations did not significantly affect myometrial collagen expression in Sham rats $(p>0.05$; Figure 6).

\section{Discussion}

MMPs are important in endometriotic tissue invasion and angiogenesis [31]. It was reported that MMPs are critical modulators of endothelia-mediated vasoconstriction in estrogen deficient animals. Through complex and obscure mechanism, estrogen replacement leads to acute MMP modulation of vascular function [32]. HRT with estrogen and progesterone might affect the MMPs expression of vascular smooth muscle cells via specific mechanisms and may lead to unbalanced MMPs regulation [33]. Stromal gelatinases expression was significantly higher in premenopausal polyps compared to postmenopausal polyps [34].

Gelatinases, including MMP-2 and -9, play central roles in the degradation of the extracellular matrix proteins, and are associated with numerous gynecological disorders, including adenomyosis [20], endometriosis [35], and endometrioid endometrial carcinoma [36]. MMP-9 is associated with endometriosis pathways and is vital for normal uterine physiology [37], whereas abnormal MMP-9 expression is associated with uterine disorder [38]. MMP-2 is one major factor involved in the invasion of endometrium and vascularization of endometriosis [39]. MMP-2 and -9 are also correlated with the processes of tumor cell invasion and metastasis in uterine neoplasms, which might be implicated in the development of uterine leiomyoma [40].

OVX rats are used as a menopausal animal model, because the biochemical and physiological changes that occur with the removal of rat ovaries are comparable to those observed in menopausal women $[26,41]$. OVX animals showed a significant decrease in the gelatinolytic activities and expression of MMP-2 and -9, and types I and III collagens in alveolar granulation tissue [42]. In OVX rats, decreased MMP-2 gelatinolytic activity has been described during skin wound healing [43]. Despite the importance of MMP family in uterus, regulation and molecular mechanisms of these proteases are poorly understood. In 
this study, we demonstrate the interactions of diosgenin and OVX upon MMP-2 and -9 expressions within uterus. It is demonstrated that OVX could reduce MMP-2 activity and produced deleterious effects mimicking menopause intrinsically [44]. Similar to previous studies [42-44], our results show a decline in the activity and gene expression of myometrial MMP-2 and -9 in OVX rats. Moreover, our findings indicate the potential roles of diosgenin upon MMP, collagen and uterine regulation. High dose supplement of diosgenin increased MMP-2 and inhibited MMP-9 activities/gene expressions in OVX rats. OVX also increased type I collagen expression in myometrial tissue as compared to Sham controls; however, which was reduced with diosgenin treatment.

MMP-2 has been demonstrated to be associated with the endometrial invasion and vascularization [39]. Therefore, it is logical to observe that administration of diosgenin increases the MMP-2 activity, which further stimulates the endometrial growth. In contrast, we also observed the inhibition of MMP-9 activity and gene expression following diogenin administration. This finding was compatible with the observation of Shishodia and Aggarwal [24], who demonstrated that diosgenin administration could downregulate the MMP-9 expression in cell lines, human myeloid KBM-5 cells and mouse macrophage Raw 264.7 cells. Another similar effect of estrogen supplement upon MMP-9 activity was reported by Seeger et al. [45], who demonstrated that estrogen supplement would decrease the MMP-9 activity in MCF-7 cells, a human estrogen and progesterone receptor-positive human breast cancer cell line.

Enhanced understanding of MMP regulation might lead to the establishment of therapies for the uterine disorders. A recent review of the MEDLINE database failed to produce studies that deal directly with diosgenin administration upon uterine MMPs expression in the menopausal/OVX uterus. In this study, our findings highlight the linkage between diosgenin, MMP-2, -9 and type I collagen. The results suggest that the absence of ovarian hormones after OVX might contribute to the abnormal uterine function by interfering with the extracellular matrix protein turnover, and might change the balance of MMP activity and collagen metabolism. These findings suggest that diosgenin administration plays a role in gelatinase expression and activity, which were associated with the uterus function of menopausal individuals. However, the thorough understanding of MMP expressions in the uterus has yet to be accomplished. Further studies are necessary to clarify the mechanisms of MMP production and activation in the uterine tissue.
In the present study, we observed that the relative influences of diosgenin on decreasing MMP-9 are dose-dependent $(10,50$, and $100 \mathrm{mg} / \mathrm{kg} /$ day) and a high dosage $(100 \mathrm{mg} / \mathrm{kg} /$ day) of diosgenin administration could increase uterine MMP-2 activity and gene expression in OVX rats. We also observed that the increased type I collagen expression in myometrial tissue of OVX rats could be reduced with diosgenin treatment. The result hints that the OVX status might be partially mended with diosgenin treatment upon the regulation of collagen expression. In this study, the increasing serum P4 was observed in Sham rats, but not in OVX rats with diosgenin administration. We do not think that the increasing serum P4 in rats is directly converted from diosgenin intake, because the lack of evidence that human body can metabolize diosgenin into progesterone, aldosterone, cortisol or estrogen. This may explain why the serum estrogen in Sham and OVX rats with diosgenin treatment is similar.

In this study, we observed that higher BW in OVX rats across the 8 weeks post surgery, although no significant differences were noted among OVX or Sham rats with diosgenin supplements. Administration of large-dosage diosgenin increased the ovarian hormone concentrations in OVX rats. These findings suggest the potential of diosgenin administration to restore gonadal hormones in OVX or menopausal individuals [10]. High doses of diosgenin can influence the regulation of gelatinase and collagen metabolism in OVX rats. It suggested that diosgenin supplement might modulate the gelatinase expression of menopause status. Abnormal glucose tolerance and metabolism have been demonstrated to be associated with menopausal status [46]. Serum calcium and phosphate are thought to be the associated marker of menopausal osteoporosis $[47,48]$. In this study, we adopted these three serum markers to detect their association with OVX status. We observed that higher serum glucose concentration, but not serum calcium and phosphorous levels, was associated with the OVX status. The discrepancy between the results observed in our OVX rats and clinical studies of menopause are likely attributed to differences in species, age of subjects, and in some cases disease status.

In conclusion, this study highlights the correlations between diosgenin supplement and gelatinase expression in OVX rats, a model of the menopausal state. Diosgenin supplementation can alter expression and activity of gelatinases in the uterine tissue of OVX rats. Adequate diosgenin supplement might regulate ovarian hormone statuses of OVX and menopause statuses. However, the underlying mechanism of the 
interaction between diosgenin and MMPs in the uterus merits further survey.

\section{Acknowledgements}

This work was supported in part by the grants of NSC 98-2313-B-009-002-MY3 from the National Science Council, Taiwan. This work was also supported by the National Science Council on Establishing "International Research-Intensive Centers of Excellence in Taiwan (I-RiCE) Project" under Contract NSC 99-2911-I-009-101.

\section{Abbreviation}

BW: body weight; E2: estradiol; GAPDH: glyceraldehyde-3-phophate- dehydrogenase; HRT: hormone replacement therapy; MMPs: matrix metalloproteinases; MMP-2: matrix metalloproteinase 2; MMP-9: matrix metalloproteinase 9; OVX: ovariectomized or ovariectomization; P4: progesterone; RT-PCR: reverse transcription-polymerase chain reaction.

\section{Conflict of Interests}

The authors have declared that no conflict of interest exists.

\section{References}

1. Studd J. Estrogens as first-choice therapy for osteoporosis prevention and treatment in women under 60. Climacteric. 2009; 12: 206-9.

2. Craig MC, Murphy DG. Estrogen therapy and Alzheimer's dementia. Ann N Y Acad Sci. 2010; 1205: 245-53.

3. Taylor HS, Manson JE. Update in hormone therapy use in menopause. J Clin Endocrinol Metab. 2011; 96: 255-64.

4. Yang XP, Reckelhoff JF. Estrogen, hormonal replacement therapy and cardiovascular disease. Curr Opin Nephrol Hypertens. 2011; 20: 133-8

5. Shook LL. An update on hormone replacement therapy: health and medicine for women: a multidisciplinary, evidence-based review of mid-life health concerns. Yale J Biol Med. 2011; 84: 39-42.

6. Stefanick ML. Postmenopausal hormone therapy and cardiovascular disease in women. Nutr Metab Cardiovasc Dis. 2010; 20: 451-8.

7. Maki PM, Sundermann E. Hormone therapy and cognitive function. Hum Reprod Update. 2009; 15: 667-81.

8. Benghuzzi H, Tucci M, Eckie R, et al. The effects of sustained delivery of diosgenin on the adrenal gland of female rats. Biomed Sci Instrum. 2003; 39: 335-40.

9. Komesaroff PA, Black CV, Cable V, et al. Effects of wild yam extract on menopausal symptoms, lipids and sex hormones in healthy menopausal women. Climacteric. 2001; 4: 144-50.

10. Wu WH, Liu LY, Chung CJ, et al. Estrogenic effect of yam ingestion in healthy postmenopausal women. J Am Coll Nutr. 2005; 24: 235-43.

11. Tucci M, Benghuzzi $\mathrm{H}$. Structural changes in the kidney associated with ovariectomy and diosgenin replacement therapy in adult female rats. Biomed Sci Instrum. 2003; 39: 341-6.

12. Tada Y, Kanda N, Haratake A, et al. Novel effects of diosgenin on skin aging. Steroids. 2009; 74: 504-11.
13. Gutiérrez-Fernández A, Inada M, Balbín M, et al. Increased inflammation delays wound healing in mice deficient in collagenase-2 (MMP-8). FASEB J. 2007; 21: 2580-91.

14. Miller MC, Manning HB, Jain A, et al. Membrane type 1 matrix metalloproteinase is a crucial promoter of synovial invasion in human rheumatoid arthritis. Arthritis Rheum. 2009; 60: 686-97.

15. Schulz R. Intracellular targets of matrix metalloproteinase-2 in cardiac disease: rationale and therapeutic approaches. Annu Rev Pharmacol. 2007; 47: 211-42.

16. Egeblad M, Werb Z. New functions for the matrix metalloproteinases in cancer progression. Nat Rev Cancer. 2002; 2: 161-74.

17. Laird SM, Widdowson R, El-Sheikhi M, et al. Expression of CXCL12 and CXCR4 in human endometrium; effects of CXCL12 on MMP production by human endometrial cells. Hum Reprod. 2011; 26: 1144-52.

18. Pan $\mathrm{CH}$, Wen $\mathrm{CH}$, Lin CS. Interplay of angiotensin II and angiotensin 1-7 in the regulations of matrix metalloproteinases of human cardiocytes. Exp Physiol. 2008; 93: 599-612.

19. Kizaki K, Ushizawa K, Takahashi T, et al. Gelatinase (MMP-2 and -9) expression profiles during gestation in the bovine endometrium. Reprod Biol Endocrinol. 2008; 6: 66.

20. Yang JH, Wu MY, Chen MJ, et al. Increased matrix metalloproteinase-2 and tissue inhibitor of metalloproteinase-1 secretion but unaffected invasiveness of endometrial stromal cells in adenomyosis. Fertil Steril. 2009; 91: 2193-8.

21. Zbucka M, Miltyk W, Bielawski T, et al. Mechanism of collagen biosynthesis up-regulation in cultured leiomyoma cells. Folia Histochem Cytobiol. 2007; 45 (Suppl 1):S181-5.

22. Bogusiewicz M, Stryjecka-Zimmer M, Postawski K, et al. Activity of matrix metalloproteinase-2 and -9 and contents of their tissue inhibitors in uterine leiomyoma and corresponding myometrium. Gynecol Endocrinol. 2007; 23: 541-6.

23. Morikawa A, Ohara $\mathrm{N}, \mathrm{Xu} \mathrm{Q}$, et al. Selective progesterone receptor modulator asoprisnil down-regulates collagen synthesis in cultured human uterine leiomyoma cells through up-regulating extracellular matrix metalloproteinase inducer. Hum Reprod. 2008; 23: 944-51.

24. Shishodia S, Aggarwal BB. Diosgenin inhibits osteoclastogenesis, invasion, and proliferation through the downregulation of Akt, I kappa B kinase activation and NF-kappa B-regulated gene expression. Oncogene. 2006; 25: 1463-73.

25. Liu MJ, Wang Z, Ju Y, et al. Diosgenin induces cell cycle arrest and apoptosis in human leukemia K562 cells with the disruption of $\mathrm{Ca}^{2+}$ homeostasis. Cancer Chemother Pharmacol. 2005; 55: 79-90.

26. Ho YJ, Wang CF, Hsu WY, et al. Psychoimmunological effects of dioscorea in ovariectomized rats: role of anxiety level. Annals of General Psychiatry. 2007; 6: 21.

27. Couse JF, Yates MM, Deroo BJ, et al. Estrogen receptor-beta is critical to granulosa cell differentiation and the ovulatory response to gonadotropins. Endocrinology. 2005; 146: 3247-62.

28. Chen CL, Lin JL, Lai LP, et al. Altered expression of FHL1, CARP, TSC-22 and P311 provide insights into complex transcriptional regulation in pacing-induced atrial fibrillation. Biochim Biophys Acta. 2007; 1772: 317-29.

29. Chen CL, Huang SKS, Lin JL, et al. Upregulation of matrix metalloproteinase-9 and tissue inhibitors of metalloproteinases in rapid atrial pacing-induced atrial fibrillation. J Mol Cell Cardiol. 2008; 45: 742-53.

30. Lin CS, Pan $\mathrm{CH}$, Wen $\mathrm{CH}$, et al. Regulation of angiotensin converting enzyme II by angiotensin peptides in human cardiofibroblasts. Peptides. 2010; 31: 1334-40.

31. Sotnikova NY, Antsiferova YS, Posiseeva LV, et al. Mechanisms regulating invasiveness and growth of endometriosis lesions in rat experimental model and in humans. Fertil Steril. 2010; 93: 2701-5. 
32. Lekontseva O, Jiang Y, Davidge ST. Estrogen replacement increases matrix metalloproteinase contribution to vasoconstriction in a rat model of menopause. J Hypertens. 2009; 27: 1602-8.

33. Grandas $\mathrm{OH}$, Mountain DJ, Kirkpatrick SS, et al. Effect of hormones on matrix metalloproteinases gene regulation in human aortic smooth muscle cells. J Surg Res. 2008; 148: 94-9.

34. Erdemoglu E, Güney M, Karahan N, et al. Expression of cyclooxygenase-2, matrix metalloproteinase-2 and matrix metalloproteinase-9 in premenopausal and postmenopausal endometrial polyps. Maturitas. 2008; 59: 268-74.

35. Han YJ, Kim HN, Yoon JK, et al. Haplotype analysis of the matrix metalloproteinase-9 gene associated with advanced-stage endometriosis. Fertil Steril. 2009; 91: 2324-30.

36. Shaco-Levy R, Sharabi S, Benharroch D, et al. Matrix metalloproteinases 2 and 9, E-cadherin, and beta-catenin expression in endometriosis, low-grade endometrial carcinoma and non-neoplastic eutopic endometrium. Eur J Obstet Gynecol Reprod Biol. 2008; 139: 226-32.

37. Swarnakar S, Paul S. Curcumin arrests endometriosis by downregulation of matrix metalloproteinase-9 activity. Indian J Biochem Biophys. 2009; 46: 59-65.

38. Nothnick WB. Regulation of uterine matrix metalloproteinase- 9 and the role of microRNAs. Semin Reprod Med. 2008; 26: 494-9.

39. Juhasz-Böss I, Hofele A, Lattrich C, et al. Matrix metalloproteinase messenger RNA expression in human endometriosis grafts cultured on a chicken chorioallantoic membrane. Fertil Steril. 2010; 94: 40-5.

40. Libra M, Scalisi A, Vella N, et al. Uterine cervical carcinoma: role of matrix metalloproteinases (review). Int J Oncol. 2009; 34: 897-903.

41. Arjmandi BH, Alekel L, Hollis BW, et al. Dietary soybean protein prevents bone loss in an ovariectomized rat model of osteoporosis. J Nutr. 1996; 126: 161-7.

42. Zecchin KG, Pereira MC, Coletta RD, et al. Ovariectomy reduces the gelatinolytic activity and expression of matrix metalloproteinases and collagen in rat molar extraction wounds. Calcif Tissue Int. 2005; 76: 136-45.

43. Pirila E, Parikka M, Ramamurthy NS, et al. Chemically modified tetracycline (CMT- 8) and estrogen promote wound healing in ovariectomized rats: effects on matrix metalloproteinase-2, membrane type 1 matrix metalloproteinase, and laminin-5 gamma2-chain. Wound Repair Regenl. 2002; 10: 38-51.

44. Shiguemoto GE, Prestes J, Leite RD, et al. Effects of resistance training on matrix metalloproteinase- 2 activity and biomechanical and physical properties of bone in ovariectomized and intact rats. Scand J Med Sci Sports. 2011; [Epub ahead of print]

45. Seeger H, Wallwiener D, Mueck AO. Effects of estradiol and progestogens on tumor-necrosis factor-alpha-induced changes of biochemical markers for breast cancer growth and metastasis. Gynecol Endocrinol. 2008; 24: 576-9.

46. Martínez-García MA, Luque-Ramírez M, San-Millán JL, et al. Body iron stores and glucose intolerance in premenopausal women: role of hyperandrogenism, insulin resistance, and genomic variants related to inflammation, oxidative stress, and iron metabolism. Diabetes Care. 2009; 32: 1525-30.

47. Adami S, Zivelonghi A, Braga V, et al. Insulin-like growth factor-1 is associated with bone formation markers, PTH and bone mineral density in healthy premenopausal women. Bone. 2010; 46: 244-7.

48. Adami S, Bianchi G, Brandi ML, et al. Determinants of bone turnover markers in healthy premenopausal women. Calcif Tissue Int. 2008; 82: 341-7. 